\title{
Kinematic Analysis of the Press Mechanism Using MSC Adams
}

\author{
Darina Hroncová, Peter Frankovský*, Ivan Virgala, Ingrid Delyová \\ Technical University of Košice, Faculty of Mechanical Engineering, Letná 9, 04200 Košice, Slovakia \\ *Corresponding author: peter.frankovsky@tuke.sk
}

Received October 6, 2014; Revised October 27, 2014; Accepted November 18, 2014

\begin{abstract}
The aim of the paper is to present the application of MSC Adams/View for kinematic analysis of a press mechanism. The press mechanism is simulated in MSC Adams/View software. MSC Adams and its modules Adams/View work with this module and its basic operation is dedicated to the solution of kinematics by means of numerical methods. Press mechanism works on the principle of converting rotational motion of a crank to translational motion of a slider block. This paper deals with model press mechanism in Adams/View, simulation running, plotting of the mechanisms points trajectory and kinematic parameters of mechanism members. The computer program shows displacement, velocity and acceleration, and angular velocity and angular acceleration. The paper presents the results with graphic display of parameters such as displacement, velocity, and acceleration.
\end{abstract}

Keywords: MSC Adams/View, press mechanism, simulation, kinematic analysis

Cite This Article: Darina Hroncová, Peter Frankovský, Ivan Virgala, and Ingrid Delyová, "Kinematic Analysis of the Press Mechanism Using MSC Adams.” American Journal of Mechanical Engineering, vol. 2, no. 7 (2014): 312-315. doi: 10.12691/ajme-2-7-30.

\section{Introduction}

Current software simulation technologies make it easy to design mechanisms with complex kinematic structure. Computer programs significantly reduce time and facilitate the work when solving practical mechanisms. Applying software simulation model, we create a mechanism which corresponds to a real machine. With computer models we can analyze in detail the solution of real objects in practice. Using computer simulations, we can expect desired behavior of the model under loads that may occur because the elimination of problems in the real system is financially much more demanding and, of course, time-consuming.

Kinematic analysis is the process of measurement of kinematic quantities which is used to describe motion. In engineering, for instance, kinematic analysis may be used to find the range of movement for a given mechanism [3]. Kinematic synthesis designs a mechanism for a desired range of motion [4].

In this paper, we deal with kinematic analysis of the press mechanism in Figure 1 which is driven by the crank which rotates with constant angular velocity.

This work deals with the simulation program MSC Adams which was used to simulate the movement of the pump mechanism. The result is presented in a graphical representation of the movement of individual elements as well as respective members of the mechanism [1]. Displacement, velocity and acceleration of key points are plotted and the trajectory of chosen points is also plotted [2].

\section{MSC Adams Main Characteristic}

Computer software MSC Adams (Automatic Dynamic Analysis of Mechanical Systems) is one of the most widely used multi-function computing software. The program allows us to create dynamic, kinematic and static analysis of the proposed mechanical systems and helps us to optimize and improve their properties. It helps in simulations of mechanical systems consisting of rigid and flexible bodies connected by different types of kinematic links and joints $[2,6,7]$.

\section{Model of the Press Mechanism}

The press mechanism works on the principle of converting rotational motion of the crank 2 to translational motion of the slider block 6 . Driving link OA has a counterclockwise angular velocity of the $6 \mathrm{rad}^{-1}{ }^{-1}$. The task is to calculate the absolute speed of the member 6 , the size of angular velocity of the member 3 , angular velocity and angular accelerations of the member 4 and kinematic parameters of other press machine members [8].

The aim of the computer simulation by MSC Adams/View is to build the model of the press mechanism. Our goal is to determine kinematic variables of rotational motion, translational motion and general plane motion of the members.

A generalized diagram of the press mechanism is shown in Figure 1. 
Member OA of the mechanism is formed by the crank and in ADAMS/View program it is a rigid body with geometry named Link. Parameters of the body 2 are as follows: length $0,15 \mathrm{~m}$, width $0,04 \mathrm{~m}$, depth $0,04 \mathrm{~m}$.

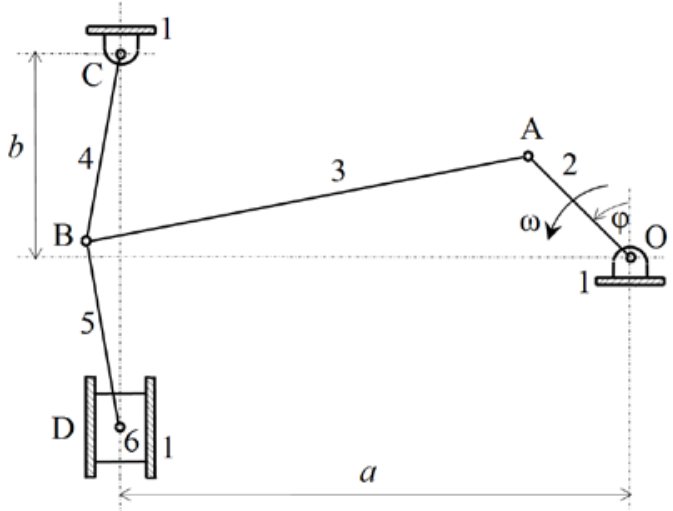

Figure 1. Model of the press mechanism

Member $\mathrm{AB}$ of the mechanism is formed by a connecting rod and in the program it is a rigid body with geometry named Link. Parameters of the body 3 are as follows: length $0,84 \mathrm{~m}$, width $0,04 \mathrm{~m}$, depth $0,04 \mathrm{~m}$.

Member BC of the mechanism is formed by the crank and in the program it is a rigid body with geometry named Link. Parameters of the body 4 are as follows: length 0,5 $\mathrm{m}$, width 0,04 m, depth 0,04 m.

Member $\mathrm{BD}$ of the mechanism is formed by the connecting rod and in the program it is a rigid body with geometry named Link. Parameters of the body 5 are as follows: length $0,7 \mathrm{~m}$, width $0,04 \mathrm{~m}$, depth $0,04 \mathrm{~m}$.

The member 6 of the mechanism is formed by a piston and in the program it is a rigid body with geometry nemed Box. Parameters of the body 6 are as follows: length $0.1 \mathrm{~m}$, width $0,16 \mathrm{~m}$, depth $0,1 \mathrm{~m}$.

Next parameters of the mechanism are angle $\varphi=45^{\circ}$, $\mathrm{a}=1,05 \mathrm{~m}$ and $\mathrm{b}=0,5 \mathrm{~m}$. The mechanism contains rotational joint, translational joint and fixed joint as shown in Figure 2b. Motion is in joint 1 in point $\mathrm{O}$ with angular velocity 6 rad. sec $^{-1}$.

Simulation parameters are: End Time 10 second and Steps 200.

\subsection{Compilation of the Model in MSC Adams}

Using basic building blocks, we compile a model of the press mechanism in MSC Adams/View (Figure 2). The model will be projected in several steps as described in the following sections [2].

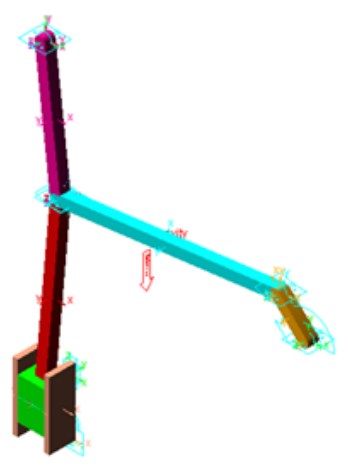

a)

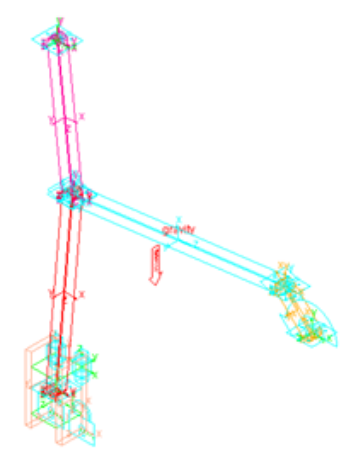

b)
Trajectory of the mass center is plotted by function Trace Marker in Figure 3. It shows trajectory of point members 3, 5 and 6.

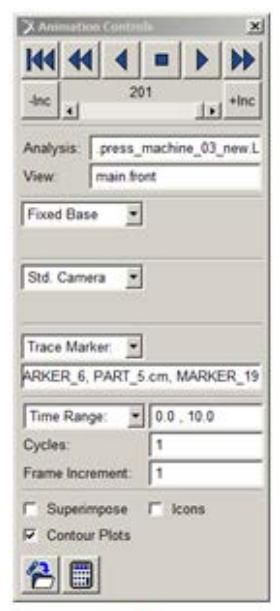

a)

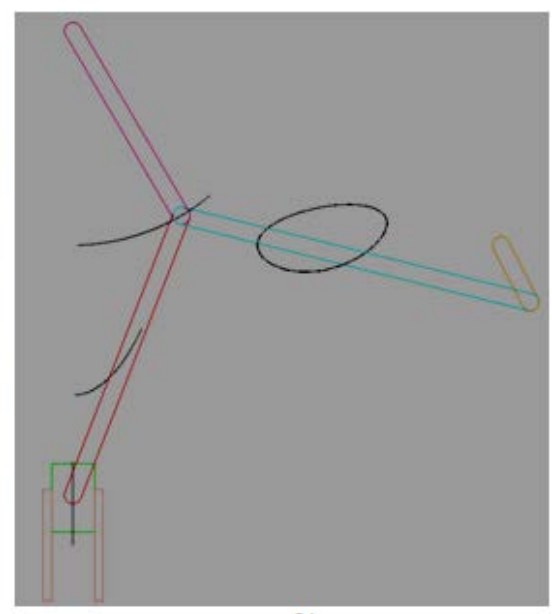

b)
Figure 3. Illustration of trace marker determines (a) animation control and (b) trajectory of respective points

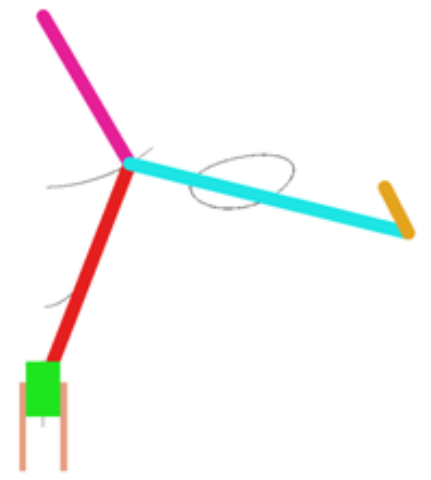

a)

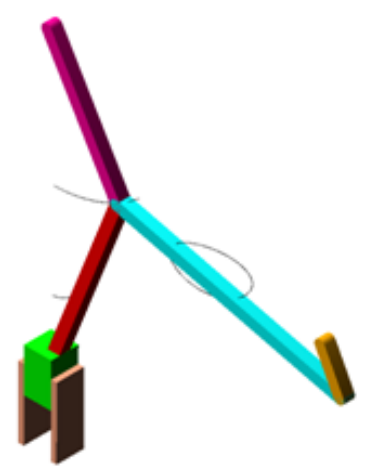

b)
Figure 4. Model of the press mechanism and trajectories with animation control (a) front view of 2D model (b) 3D model

\subsection{Creating Kinematic Variables of the Member 2}

To determine the values of the parameters it is necessary to define several properties in measurement windows [1]. After opening the dialog box for the determined angle, velocity and acceleration, is necessary to define important parameters $[3,4]$. The time course angle of rotation member 2 is shown in Figure 5.

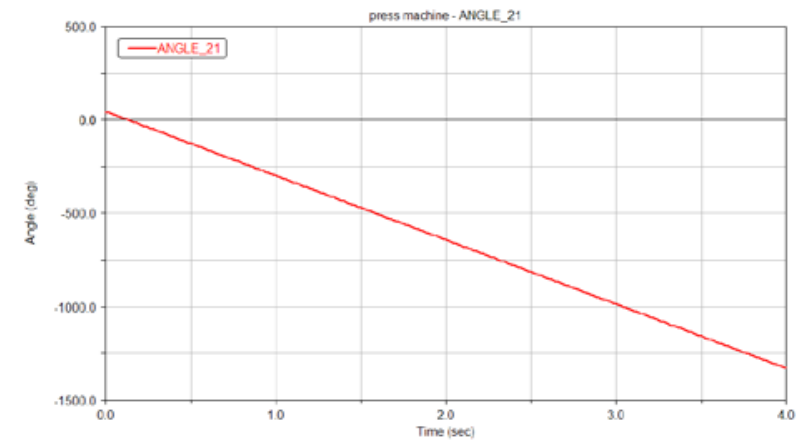

Figure 5. Rotation angle of the crank 2 


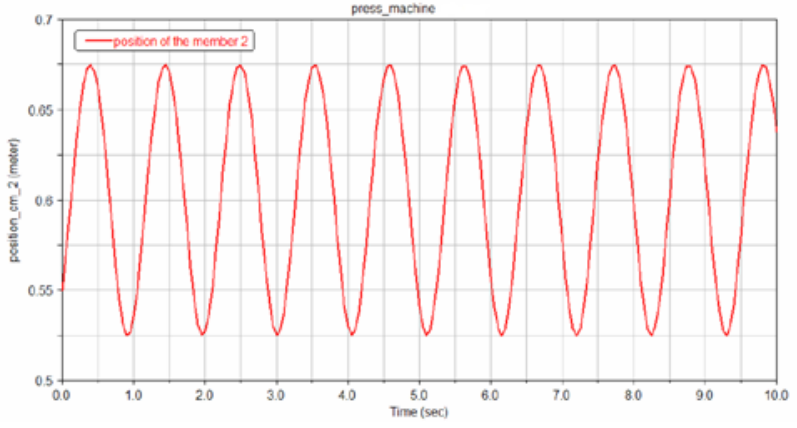

Figure 6. Position of the crank mass centre - PART_2

Angular velocity of the PART_2 is 343,77 rad.sec ${ }^{-1}$ (Figure 7).

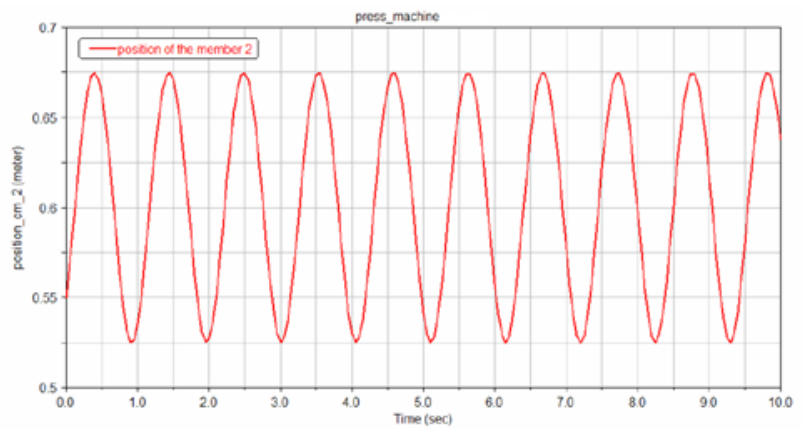

Figure 7. Angular velocity of the crank mass centre - PART_2

\subsection{Creating Kinematic Variables of the Member 6}

Figure 8 shows an example of measurement windows with kinematics parameter of the point $\mathrm{D}$ member 6 .

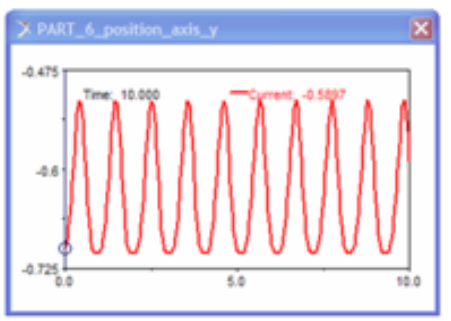

a)

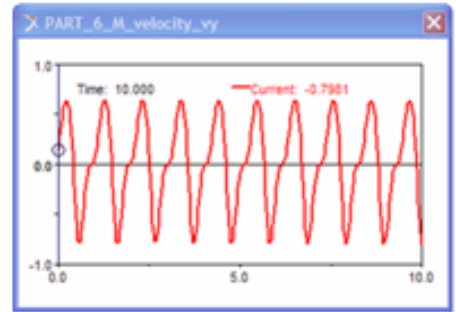

b)

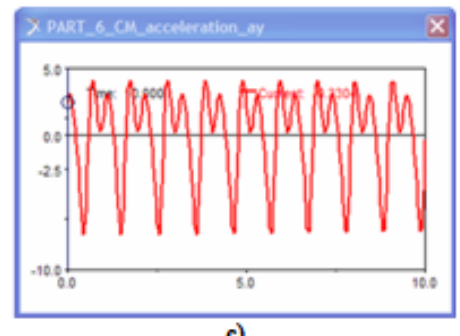

Figure 8. Measurements with kinematic parameters of the point D PART_6 a) displacement $\mathrm{y}$, b) velocity $\mathrm{v}_{\mathrm{y}}, \mathrm{c}$ ) acceleration $\mathrm{a}_{\mathrm{y}}$

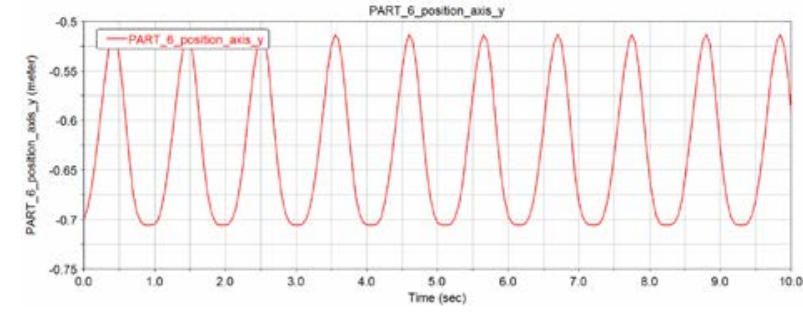

Figure 9. Kinematic parameters of the point D-position

Dependence of kinematic variable of velocity of the member 6 from time is shown in Figure 10.

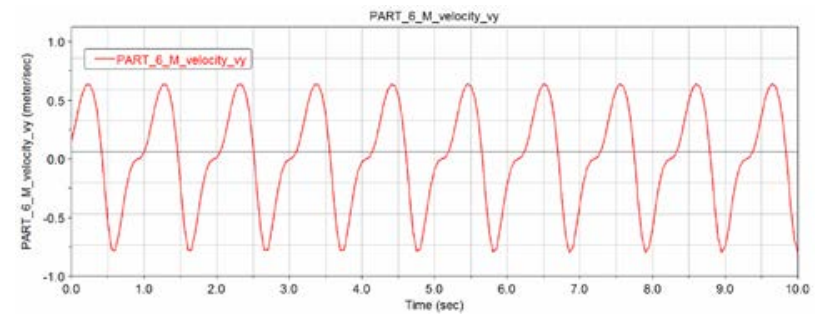

Figure 10. Kinematic parameters of the point D-acceleration

The following picture (Figure 11) demonstrates acceleration of point $\mathrm{D}$ in the member 6 in graphical form.

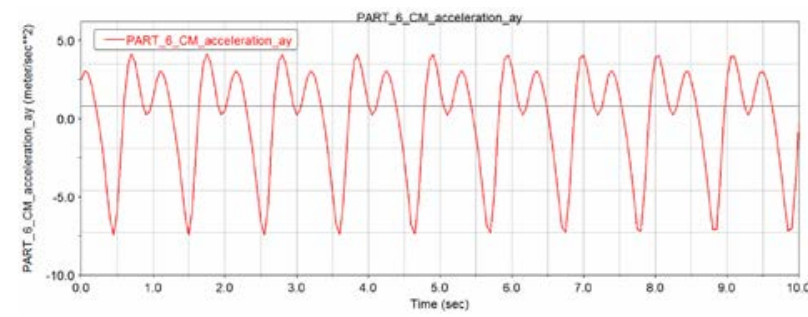

Figure 11. Kinematic parameters of the point D-velocity

\subsection{Creating Kinematic Variables of the Member 6}

Dependence of kinematic variables of angular velocity of the member 3 from time is shown in Figure 12.

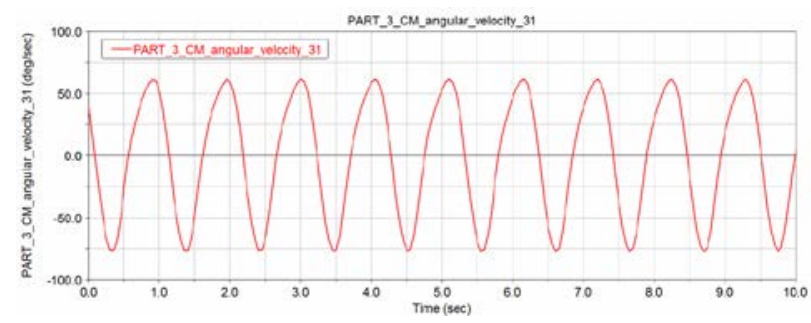

Figure 12. Angular velocity of the member 3 -PART_3

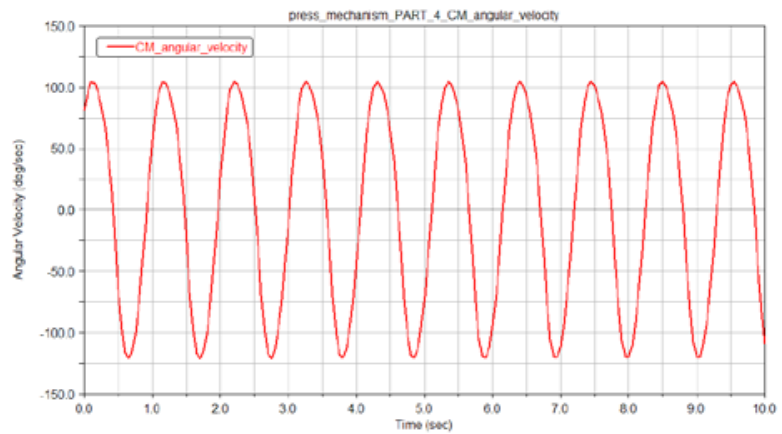

Figure 13. Angular velocity of the member 4 - PART_4 


\subsection{Creating Kinematic Variables of the Member 4}

Dependence of kinematic variables of angular velocity of the member 4 from time are shown in Figure 13.

Dependence of kinematic variables of angular acceleration of the member 4 from time is shown in Figure 14.

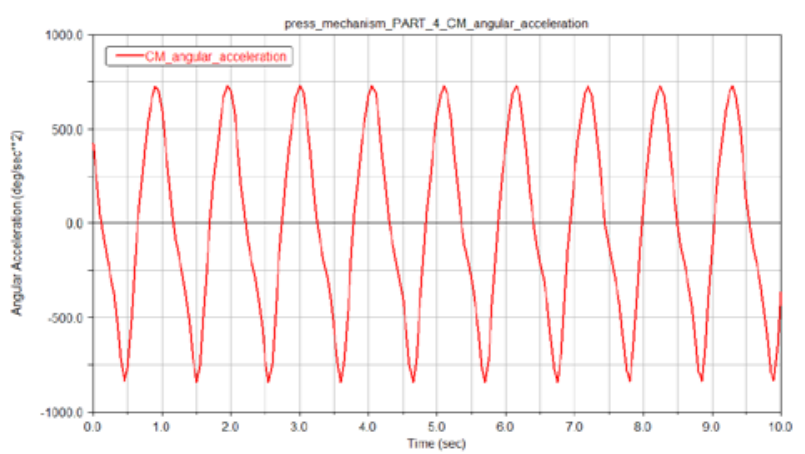

Figure 14. Angular acceleration of the member 4 -PART_4

\subsection{Creating Kinematic Variables of the Member 4}

The diagram in Figure 15 shows the dependence of angular velocity from time of the member 5 .

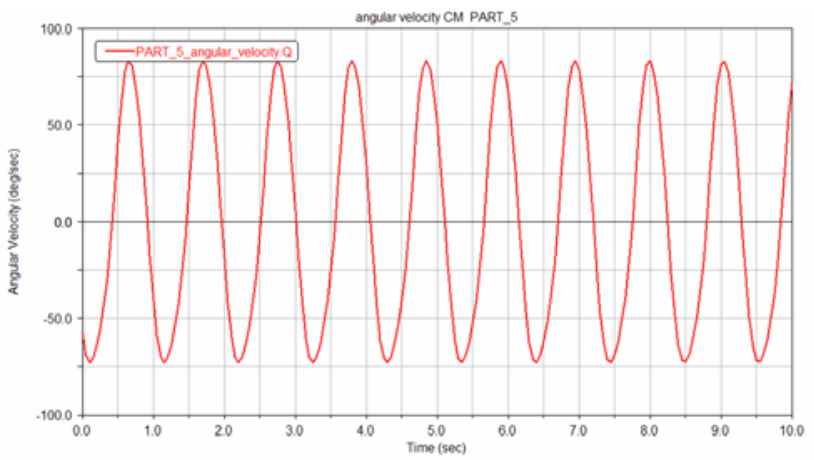

Figure 15. Angular velocity of the member 5 - PART_5

The diagram in Figure 16 shows the dependence of angular acceleration from time of the member 5 .

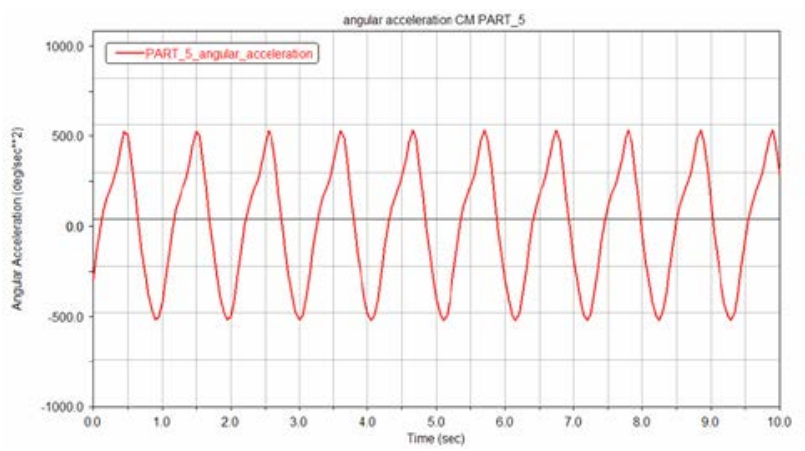

Figure 16. Angular acceleration of the member 5 - PART_5

Creating animation file of press mechanism is shown in Figure 17.

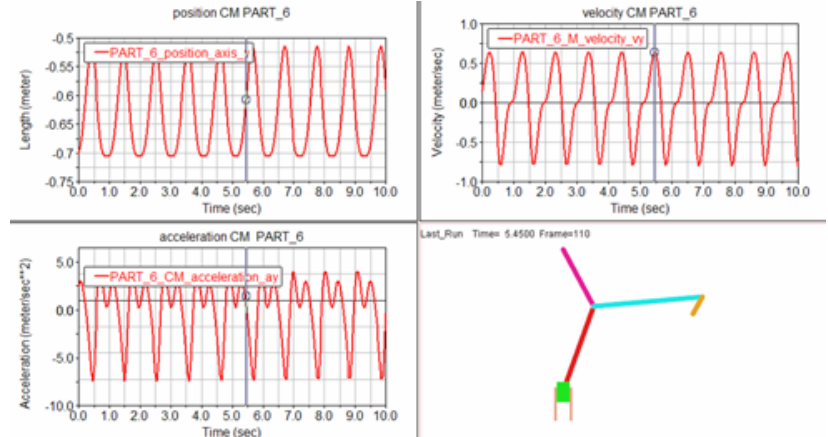

Figure 17. Kinematic parameters of the member 6 and animation in the same window

\section{Summary}

Great benefit of the study is the familiarity with the issues and new opportunities to learn how to work with the simulation program MSC ADAMS/View, which is used for modeling systems of more degrees of freedom, their static, kinematics and dynamic analysis [3-4]. The result of the simulation enables a graphical and numerical form [2]. Diagrams of kinematic variables were created in Adams/Postprocessor, one of the modules of the program MSC Adams/View. The program allows us to create a video file in *. avi format as shown in Figure 17.

In such form, the article may serve educational purposes to find out more about simulation in software MSC ADAMS/View.

\section{Acknowledgement}

This paper was supported in part by the Ministry of Education of the Slovak Foundation under KEGA projects No. 054 TUKE - 4/2014 "Using of modern numerical methods of mechanics as a base of scientific design to the development of knowledge base of students at the second and third level of university studies" and KEGA No. KEGA 004TUKE-4/2013.

\section{References}

[1] Delyová, I., Frankovský, P., Hroncová, D., "Kinematic analysis of movement of a point of a simple mechanism," 4th International Conference Modelling of mechanical and mechatronic systems, Technical University Košice, Herl'any, Slovakia, 2011.

[2] Hajžman, M., Help text for an introduction to the basics of working with the system ADAMS, Information on http://www.kme.zcu.cz/mhajzman/download/adams_zaklad.pdf.

[3] Juliš, K., Brepta, R., Mechanika I.díl, Statika a Kinematika [Mechanics Part I, Statics and Kinematics], SNTL, Praha, 1987.

[4] Stejskal, V., Valášek, M., Kinematics and dynamics of Machinery, Marcel Dekker, Inc., New York, 1996.

[5] Kuryło, P., Papacz, W., "Wykorzystanie pakietu Matlab Simulink w modelowaniu zjawiska tarcia," Tehnologiâ, L. E. Švarcburg, Moskva: Moskovskij Gosudarstvennyj Tehnologičeskij Universitet Stankin, 2011, s. 207-218. ISBN: 978-5-8037-0420-1.

[6] Ángel, L., Pérez, M. P., Díaz-Quintero, C., \& Mendoza, C., "ADAMS/MATLAB Co-Simulation: Dynamic Systems Analysis and Control Tool,” Applied Mechanics and Materials, 232, 527-531.

[7] Božek, P., "Robot path optimization for spot welding applications in automotive industry,” Tehnički vjesnik, 20 (5), 913-917.

[8] Hroncová, D., Delyová, I., Frankovský, P., "Kinematic Analysis of Mechanisms Using MSC Adams,” In: Applied Mechanics and Materials. 2014. p. 83-89. 